\title{
Evaluation of the E-PRTR emissions inventory: the Galician case
}

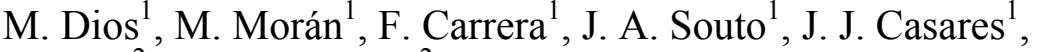 \\ A. Díaz ${ }^{2} \&$ M. L. Macho ${ }^{2}$ \\ ${ }^{1}$ University of Santiago de Compostela, Spain \\ ${ }^{2}$ Laboratorio de Medio Ambiente de Galicia, Consellería de Medio \\ Ambiente, Territorio e Infraestructuras, Xunta de Galicia, Spain
}

\begin{abstract}
Since 2008, E-PRTR is the European Emissions and Transfer Register of Pollutants, which was set to accomplish the UNECE Aarhus Convention about the information, public participation in decisions and access to the judgement in environmental issues. This pollutants emissions inventory follows a methodology based in the imperative declaration of emissions into the atmosphere and to water by the potential sources, included in the Directive 96/61/CE. As a consequence, the accuracy of this inventory depends on the information declared by the sources. In this work, a systematic methodology to validate the declared emissions was designed and applied to the Galician region. This methodology is based in a data structure of plant/activity-process-sourcepollutant, that is, a flowsheeting analysis of every plant was developed in order to associate each process to each source (i.e. chimney) at the same plant; with this approach, estimation of the pollutants emissions from every source is obtained by the calculation of emissions by process, based in different emissions factors. Of course, complementary data from the processes (i.e. fuel consumption, energy production, ...) is required.

Results of the E-PRTR for 2008 and 2010 years at Galicia show significant differences between the emissions distribution by sector, depending on the pollutant; this can be explained by changes in the processes technologies and performance. About the validation, in a first stage less than $50 \%$ of the sources provided acceptable emissions with the complementary information for validation; some of them complete this information upon request.
\end{abstract}

Keywords: emissions inventory, validation data, emission calculation methodology, E-PRTR. 


\section{Introduction}

The Application of E-PRTR (Pollution Release and Transfer Register) in Galicia allows for the information about the industrial activities included and the related air and water emissions and solid waste disposal to be compiled. These emissions data are publicly available for each industry [1].

The installations included in Annex I to the E-PRTR Regulation are obliged to report their emissions, if the applicable capacity threshold(s) is exceeded. This is voluntary for the rest. Previous investigations show more effective and faster reductions in emissions with voluntary actions than regulatory [3, 4].

Based on the data collected in the E-PRTR, emission temporal series can be identified. Thus, by means of bottom-up analysis individual trends for installation and CORINAIR sectors can be evaluated. These trends are poorly represented in top-down analysis [5].

The publication of the emission data lead to the installations to improve their productive processes, stimulating the implementation of clean technologies, and, consequently, a decrease in the emissions and the associated control costs [6].

A validation of the reported data is required in order to correct possible mistakes before being published in the E-PRTR. Saarinen (2003) [7] shows the variability of the quality in the reported emissions in Finland. A standardize publishing process is required, in order to obtain a better accuracy for comparison and interpretation of the emissions data.

This work proposes a methodology for the evaluation of the Pollution Release and Transfer Register inventory for Galicia (E-PRTR). Also, an analysis of the obtained results for pollutants emissions from 2008 and 2010 E-PRTR was done, studying the errors done by installations in the provided data. The validation methodology is based on the analysis of the flowsheet for each installation, assigning to each plant or activity its corresponding sub-process, emission sources and related pollutants. Now, the emissions from each plant are obtained as the sum of each process emissions, calculated by means of internationally recognized emissions factors. Additional information is required for each process (i.e., fuel consumption, energy production, etc.) [2].

\section{Methodology}

\subsection{Emission calculation methodology}

The methodology for setting up the emissions inventory was proposed by Casares et al. [2]. A bottom-up approach is used, so a deep knowledge of the processes of each installation is necessary.

The first stage of the methodology is called installation to installation, defining the flow sheeting.

Once this flow sheeting has been defined, the next stage is the selection and application of the emissions calculation methods. The selection of the calculation method follows the flow diagram shown in Figure 1 depending on the available data. 


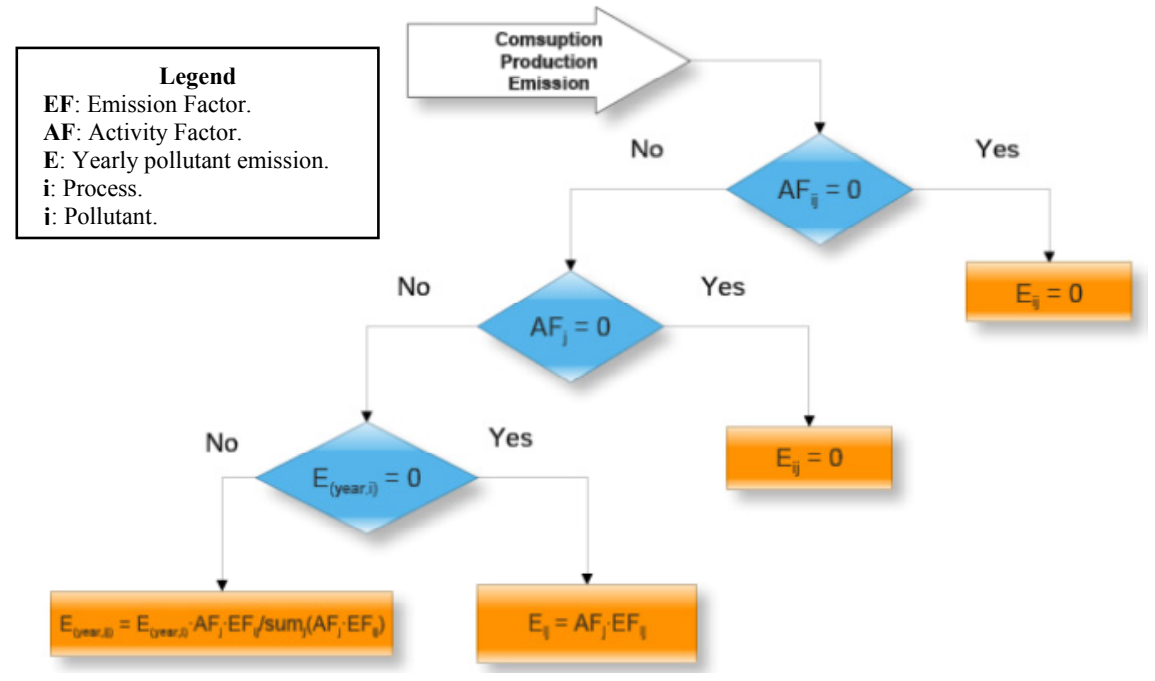

Figure 1: $\quad$ Flow diagram for the selection of the emissions calculation method based on the available data.

The emission calculation exposed in the flow diagram on Figure 1 has the required input data values of consumption, production and pollutant emission associated with each pollutant for each process. According to this flow diagram, if the emission factor for the pollutant in the process $\mathrm{j}$, or the quantification process variable $\mathrm{j}$, are zero, the emission ij is also zero. If previous conditions are not met, then assess the declared emission of the pollutant for that year is zero, if it is true, calculate the emission ij with the quantification variable $\mathrm{j}$ and the emission factor $\mathrm{ij}$, otherwise the emission $\mathrm{ij}$ is obtained as the contribution of the process evaluated the global emission of the pollutant.

Reported installations data are classified as measured, calculated or estimated depending on the selected calculation method. Information provided in releases and transfers off-site must be based on measurement, calculation or estimation. When using this simplified methodology, data are classified into three categories identified by a letter code based on the method used for determination:-

-Method M: Release data are based on measurements ("M"). To obtain emission data for the reference year, additional calculations may be necessary considering flows, flowsheeting or other data of the process. When the data come from either emission control systems or process monitoring (both continuous and discontinuous), "M" method is considered. Also, when the annual emissions are determined based on sporadic source measurements, "M" code is considered.

- Method C: Emissions data are based on standard calculations ("C"). Should be shown with "C" emission values obtained from emission factors, mass balances and other calculations using process variables such as fuel, production rates, etc. In some cases calculation methods can be used more complex, based on variables such as temperature, global radiation, and so on. 
- Method E: Emissions data are based on non-standard estimations ("E"). It must be identified as "E", when the emissions are determined based on opinions or experiences of experts as reference methods, or in lacl of standards for the estimation of emissions; even, when based on the application of guidelines of good practices.

\subsection{Validation methodology}

The emissions data reported by the installations are submitted to the validation procedure for their approval, correction or rejection, before being incorporated in E-PRTR register/inventory. The logic flow represented in Figure 2 shows the structure of the validation procedure.

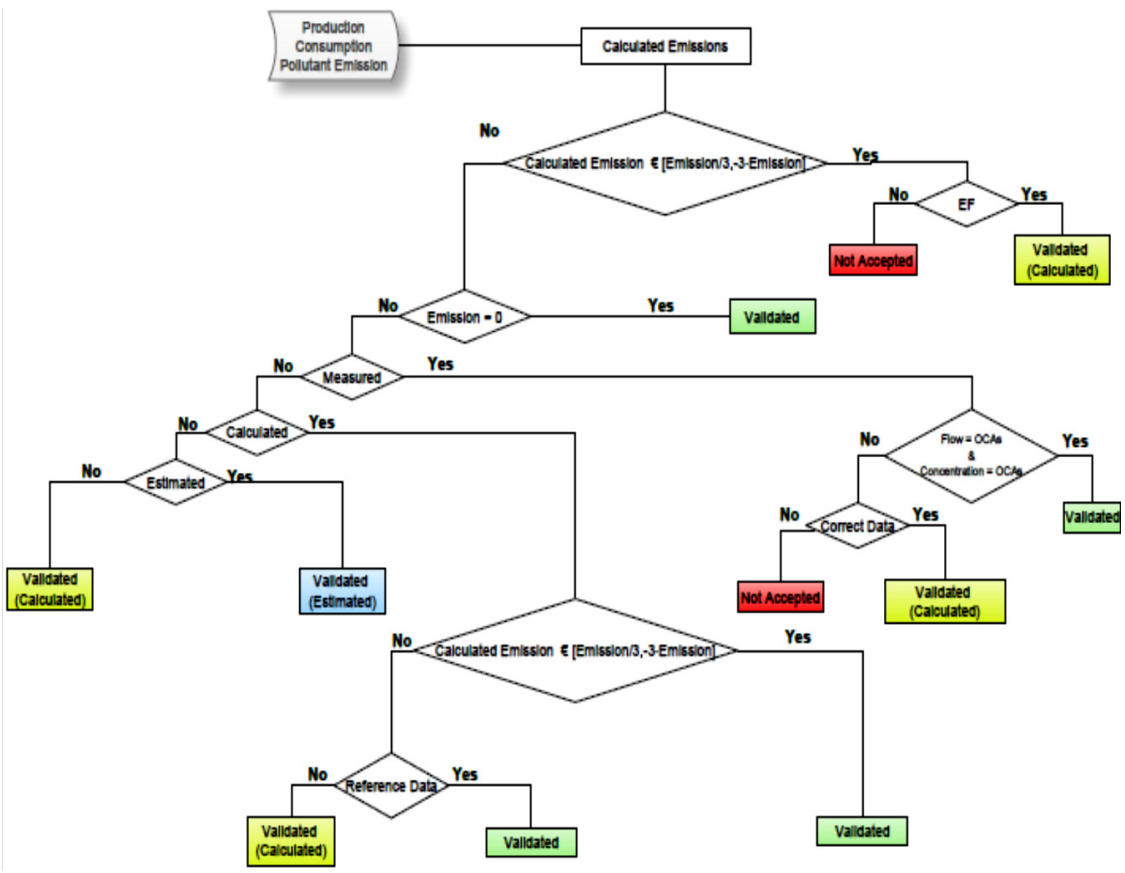

Figure 2: Flow diagram of the validation procedure for the E-PRTR emissions data.

Emissions calculated according to the methodology described above serve as input to the flow diagram of Figure 2 for the validation of the emission. If the calculated emission in the interval [3 Declared Emission, $\left.\frac{\text { Declared Emission }}{3}\right]$ and there is an emission factor, then the emission is validated reported as calculated. In the absence of an emission factor is not accepted the emission declared.

If the emission does not belong to the range calculated above, it checks whether its value is zero, and if so, validate the data. Then, the diagram leads to 
the next logical level to decide if the emission is declared as (M): if it is true and the value consistent with those reported by Institutions for Certified Measurements (ICMs), is validated and reported as measured, if the emission does not match with the certified values for ICMs, the value is declared as calculated.

\section{Results and discussion}

\subsection{Overall results}

Considering Annex I of the E-PRTR, the industrial plants which must report their emissions identified at Galicia, were 139 in the year 2008 and 133 in the year 2010. Also, the reported pollutants decreased in $5.6 \%$.

The validation methodology was applied to both 2008 and 2010 emissions datasets, obtaining the overall results shown in Table 2.

Table 2: Total emissions to the atmosphere reported in 2008 and 2010 (kg/year) from Galicia.

\begin{tabular}{|c|c|c|c|c|c|c|}
\hline & \multicolumn{7}{|c|}{ TOTAL emissions (kg/year) } \\
\hline Year & CO & SOx & NOx & PM $_{\mathbf{1 0}}$ & $\mathbf{C O}_{\mathbf{2}}$ & $\begin{array}{c}\text { Heavy } \\
\text { metals }\end{array}$ \\
\hline $\mathbf{2 0 0 8}$ & 28084194 & 34420945 & 27275942 & 4374290 & 14849187200 & 21203 \\
\hline $\mathbf{2 0 1 0}$ & 30883943 & 24483904 & 19422483 & 2150522 & 11210879182 & 10444 \\
\hline Change & 10 & -29 & -29 & -51 & -25 & -51 \\
\hline
\end{tabular}

Following the different industrial activities (included in the Annex I to the EPRTR) emissions distributions by activity were compared for 2008 and 2010 years, pollutant by pollutant.

Figure 3 shows CO emissions distributions, where $70 \%$ of emissions to the atmosphere correspond to the energy activities, with significant contributions of paper, wood and other commodities.

In addition, a $10 \%$ of increment in the total amount of $\mathrm{CO}$ emitted in 2010 is observed (Table 2). Comparing this increment with the $25 \%$ of decrease of the $\mathrm{CO}_{2}$ emission could indicate a lower performance of the combustion systems installed in power production installations, favouring the incomplete combustion, or a drop in the efficiency of production processes.

A relevant example is the installation of Alcoa Inespal - La Coruña (Metals production and processing) where the $\mathrm{CO}_{2}$ emission decreased by $1.2 \%$, while $\mathrm{CO}$ emission increased by $700 \%$. Although no raw material data in 2008 are available in 2008, Aluminum production decreased by $7 \%$ following $\mathrm{CO}_{2}$ emissions drop; therefore, $\mathrm{CO}$ emission increment is not justified. 

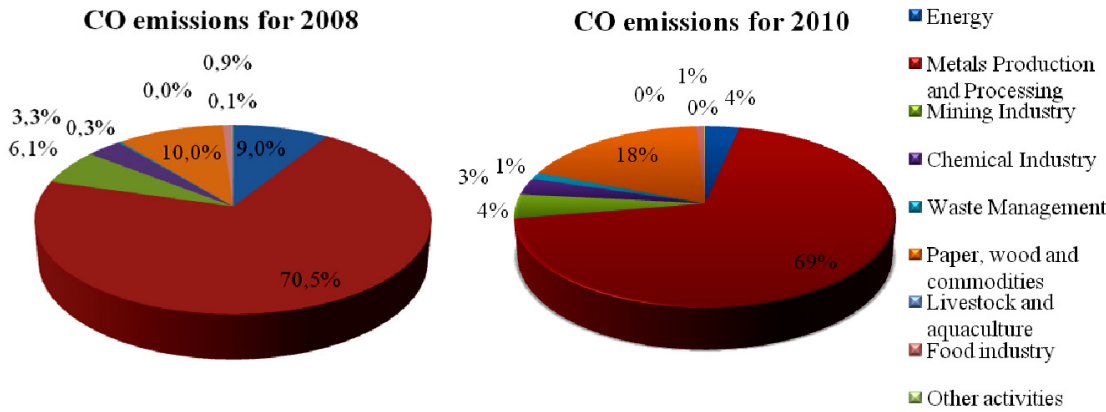

Figure 3: $\quad \mathrm{CO}$ emissions distributions to the atmosphere in 2008 and 2010, by industrial activity.

Figure 4 shows the SOx emissions distributions by industrial activity. Two activities, energy installations and metals production and processing, represent over $80 \%$ of SOx total emissions, while other relevant activities include paper industries, wood and other commodities $7.6 \%$ in 2010. Globally, sulfur oxides emissions decreased 29\% (Table 2). This can be well explained because Endesa As Pontes Power Plant, which is included in Energy activities, stopped to partially burn local lignite $(2.5-3 \%$ of sulfur) in 2008 , which was completely swapped by sub-bituminous coal ( $0.1 \%$ of sulphur); so a reduction of $55 \%$ in SOx emissions was achieved. As a consequence, the highest 2010 SOx emission value correspond to Repsol YPF Industrial Complex A Coruña.
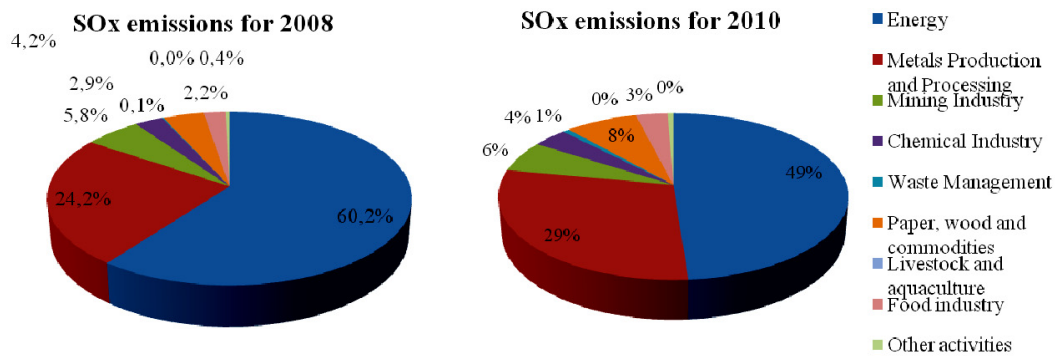

Figure 4: SOx atmospheric emissions distributions in 2008 and 2010 by industrial activity.

In NOx emissions distributions (Figure 5), energy activities and production and processing of metals released to the atmosphere cover almost $70 \%$ of total emissions; in addition, food industry, with 15 and 10.5\% in 2008 and 2010, respectively, is remarkable activity for such emissions. 

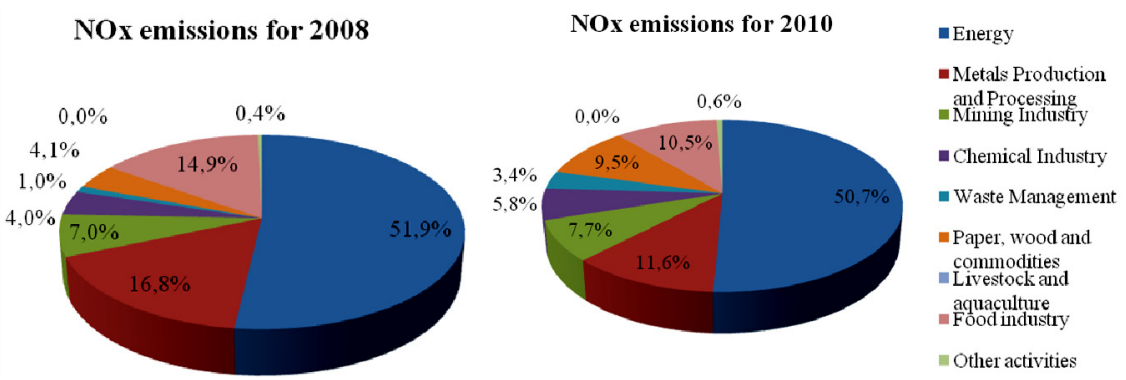

Figure 5: NOx atmospheric emissions distributions in 2008 and 2010 by industrial activity.

Although metals production and processing reduced their NOx emission percentage in 2010, particularly the installation of Alcoa Inespal - La Coruña increased by $98 \%$ of NOx emissions reported between both years.

Figure 6 shows a great reduction on global emissions of PM10 in both metals production and processing and energy activities, with $74 \%$ and $54 \%$ for the years 2008 and 2010, respectively. Activities related to paper, wood and commodities represent 15\% in 2008 and just over a quarter of the global emission in 2010.
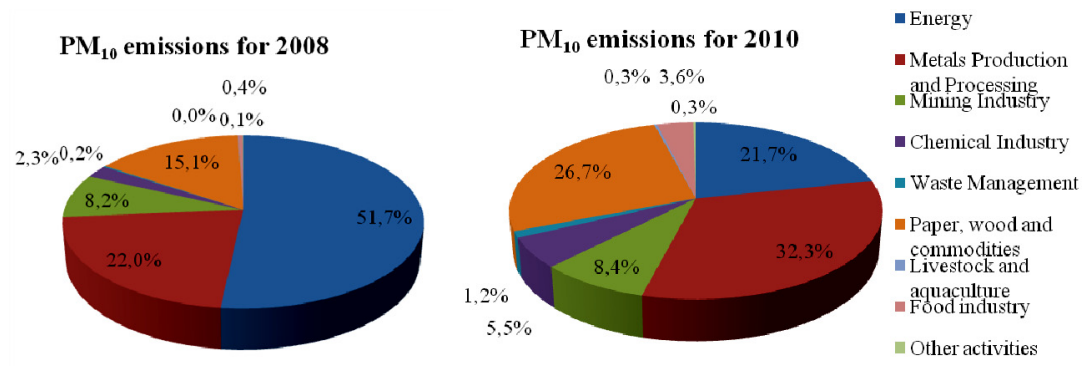

Figure 6: PM10 atmospheric emissions in 2008 and 2010 by industrial activity.

The amount of PM10 was reduced by 51\% for the period 2008-2010 (Table 2). This may be due to a reduction of $87 \%$ of A Coruña Repsol YPF Refinery in 2008, when it represented $34 \%$ of the total, and just a $9 \%$ in 2010.

The total emissions of $\mathrm{CO}_{2}$ into the atmosphere, Figure 7 , are around $80 \%$ due to the metals production and processing and energy activities.

Overall $\mathrm{CO}_{2}$ emission is reduced by $25 \%$ (Table 2). This phenomenon may be associated to the decrease of 36\% experimented by Endesa As Pontes Power Plant, as it represented $47 \%$ of the overall in 2008 , reduced to $39 \%$ in 2010 . 

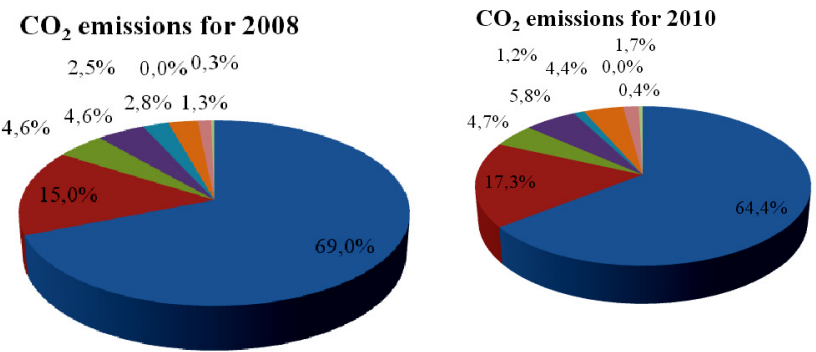

- Energy

- Metals Production

and Processing

Chemical Industry

- Waste

Management

Livestock and

aquaculture

- Other activities

Figure 7: $\quad \mathrm{CO}_{2}$ atmospheric emissions distributions in 2008 and 2010 by industrial activity.

Atmospheric heavy metal emissions distribution (Figure 8) suffered a significant change from 2008 to 2010 . In 2008 emissions are mainly due to the activities of paper, wood and commodities, with less contribution of energy activities and metals production and processing. Otherwise, in 2010 the main emissions relates to activities of paper, timber and commodities.

Heavy metals emissions for 2008

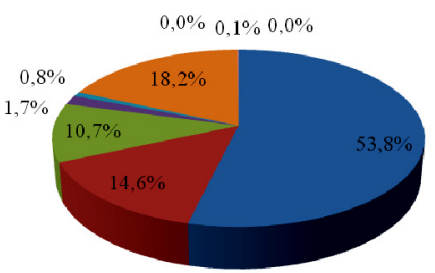

Heavy metals emissions for 2010

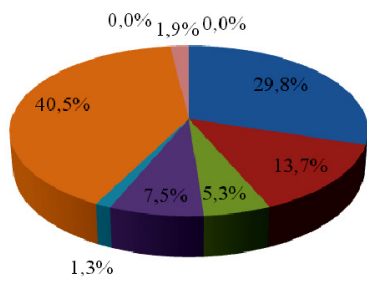

- Energy

- Metals Production a Mining Industry

- Chemical Industry

- Waste Management

- Paper, wood and

commodities
Livestock and aquaculture Foodindistry

- Other activities

Figure 8: Heavy metals atmospheric emissions distributions in 2008 and 2010 by industrial activity.

\subsection{Causes of errors}

When data reported by installations are either corrected or rejected, different errors were identified and classified as causes of them.

Table 3 shows the different categories of errors and a short description of them. The analysis is performed taking into account even though the emission data is validated, if the installation makes a mistake in its report. 
Table 3: Classification of errors in the emissions data provided by the installations, with a short description of them.

\begin{tabular}{|c|c|}
\hline Type of error & Description \\
\hline $\begin{array}{c}\text { Type 1: } \\
\text { Errors related to } \\
\text { the non- } \\
\text { declaration }\end{array}$ & $\begin{array}{l}\text { The installation declares not to be affected by the RD } \\
508 / 2007 \text {, but according to the information provided } \\
\text { must report their emissions. } \\
\text { Existence of non-declared emission sources and } \\
\text { substances that present significant emissions, so they } \\
\text { should be included in the declaration. }\end{array}$ \\
\hline $\begin{array}{c}\text { Type 2: } \\
\text { No information }\end{array}$ & $\begin{array}{c}\text { Lack of activity parameters: consumption and fuel } \\
\text { type, hours of operation of each source, production, } \\
\text { average concentrations. } \\
\text { Lack of documentation supporting the emissions } \\
\text { calculations: material balance, selected emission } \\
\text { factors depending on the type of process, analytical } \\
\text { and analytical methods. }\end{array}$ \\
\hline $\begin{array}{l}\text { Type 3: } \\
\text { Error the } \\
\text { calculations }\end{array}$ & $\begin{array}{c}\text { Miss-identification of emission flow with another } \\
\text { parameter. } \\
\text { Wrong units. } \\
\text { Error in the combination of several sources. } \\
\text { Specific errors: COD } / 3 \text {, total particle identification } \\
\text { PM }_{10} \text {, NMVOC identification of COT. } \\
\text { Wrong selection of the emission factor. }^{\text {Wron }}\end{array}$ \\
\hline $\begin{array}{c}\text { Type 4: } \\
\text { Lower level errors }\end{array}$ & $\begin{array}{l}\text { The limit of detection of the selected analytical method } \\
\text { is not achieved, so that must be reported as estimated. } \\
\text { Variation of detection limit is not allowed, so it is } \\
\text { necessary to establish a single analytical method. } \\
\text { Miss-reporting. Erroneous calculated data, when } \\
\text { measured and vice versa. } \\
\text { Measures are not representative of this emission. }\end{array}$ \\
\hline $\begin{array}{c}\text { Type 5: } \\
\text { No admission of } \\
\text { the declaration of } \\
0 \mathrm{~kg} / \text { year emission } \\
\end{array}$ & $\begin{array}{l}\text { When not included in the declaration of substances } \\
\text { that either are not measured or no emission factors are } \\
\text { available for them. }\end{array}$ \\
\hline $\begin{array}{l}\text { Type 6: } \\
\text { Uncorrected } \\
\text { errors in the } \\
\text { extension }\end{array}$ & $\begin{array}{c}\text { The extension of the complementary information } \\
\text { supplied by the installation is not enough to do the } \\
\text { validation of emissions. }\end{array}$ \\
\hline
\end{tabular}

The results of the E-PRTR for years 2008 and 2010 in Galicia show significant differences between the emissions distribution by activity. For this reason, a statistical analysis of the most common mistakes committed by the facilities in the declaration of its emissions in 2008 and 2010 was performed. The statistics are shown in Figure 8. 
Pollutants emissions 2008

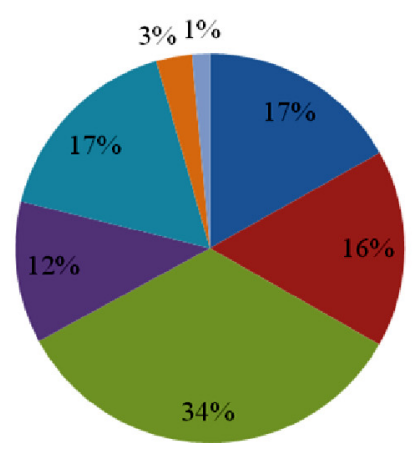

Pollutants emissions 2010

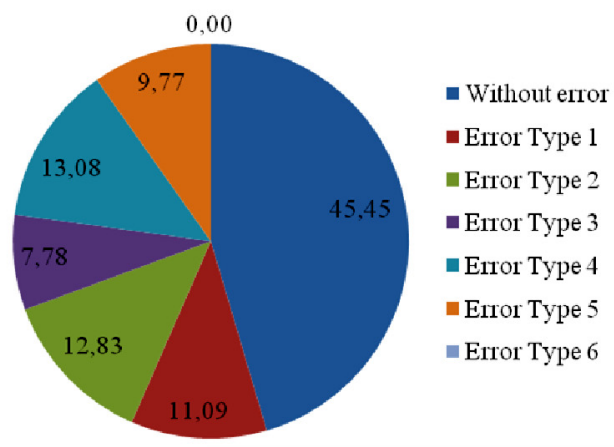

Figure 9: Statistical analysis of the reported emissions errors types in 2008 and 2010.

For year 2010 , only $45 \%$ of reported atmospheric emissions data were accepted without any correction, while for 2008 they were just $17 \%$. The most common error in 2008 was type 2, however in 2010 the percentages are homogeneously distributed. This increment of valid data in 2010 was due to a greater contribution of complementary information provided by the installations, in order to justify their reported emissions.

\section{Concluding remarks}

A methodology for the evaluation of the Pollution Release and Transfer Register inventory (E-PRTR) was presented and tested over Galicia region. A comparison of their results between 2008 and 2010 E-PRTR inventories evaluation shows that the industrial activities of production and processing of metals and energy represent the highest weight of atmospheric emissions for most of the species. These activities represent a relative weight greater than $50 \%$ of total emissions, except the $45 \%$ of heavy metals.

However, differences in the pollutants distributions by industrial activity were observed between both years, depending on the pollutant considered. Most of them can be explained by different improvements in the production technologies of specific sources, with an exception in $\mathrm{CO}$ emissions only explained by poor efficiency of specific combustion units.

About the validity of this inventory, valid data (without corrections) were increased between 2008 and 2010, due to the increment of the complementary information provided by the installations; remarking the significance of these data to obtain a realistic E-PRTR emissions inventory. 


\section{Acknowledgements}

This work was developed with the financial support of Laboratorio de Medio Ambiente de Galicia (Xunta de Galicia), and the project "XIMERE/FUXIMERE" (10MDS009E) (PGIDT, Xunta de Galicia). The Galician regional 'Consellería de Innovación e Industria' is acknowledged for the PhD grant of M. Dios ('María Barbeito' Programme, Xunta de Galicia).

\section{References}

[1] European Commission, 2006. Guidance for the implementation of the European PRTR.

[2] Casares, J.J., Rodríguez, R., Maceira, P., Souto, J.A., Ramos, S., Costoya, M., Sáez, A., 2005, Inventory, analysis and projection of industrial air pollution emissions in Galicia. University of Santiago de Compostela, Spain (in Spanish).

[3] Khanna, M., Quimio, W.R.H., Bojilova, D., 1998. Toxics release information: a policy tool for environmental protection. Journal of Environmental Economics and Management (36), 243-266.

[4] Gamper-Rabindran, S., 2006. Did the EPA's voluntary industrial toxics program reduce emissions? A GIS analysis of distributional impacts and bymedia analysis of substitution. Journal of Environmental Economics and Management (52), 391-410.

[5] Styles, D., O'Leary, E., Jones, M.B. 2009. Measuring the environmental performance of IPPC industry: II. Applying the environmental emissions index to quantify environmental performance trends from routinely reported data. Environmental Science \& Policy. (12), 243-256.

[6] Frondel, M., Horbach, J., Rennings, K., 2007. End-of-pipe or cleaner production? An empirical comparison of environmental innovation decisions across OECD countries. Business Strategy and the Environment 16 (8), 571584.

[7] Saarinen, K. 2003. A method to improve the international comparability of emission data from industrial installations. Environmental Science \& Policy 6 (2003) 355-366. 